E-376

(Revised)
Issued April 1936

Revised March 1937

United States Department of Agriculture Bureau of Entomology and Plant Quarantine

RECOMMENDATIONS FOR THE CONTROL OF INSECTS ATTACKING CERTAIN

VEGETABLES, SMALL FRUITS, AND TOBACCO

By W. H. White, Division of Truck Crop

and Garden Insect Investigations 


\section{Contents}

Page

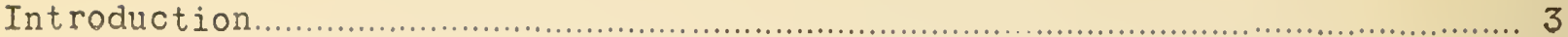

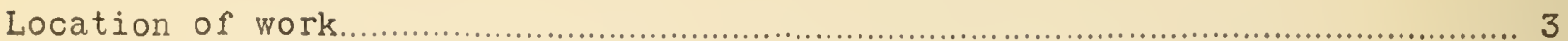

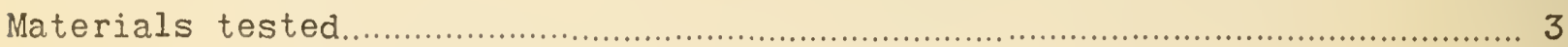

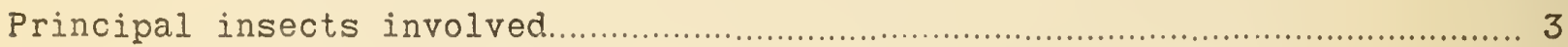

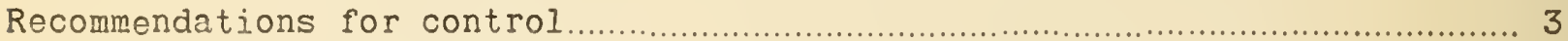

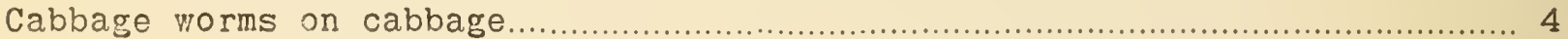

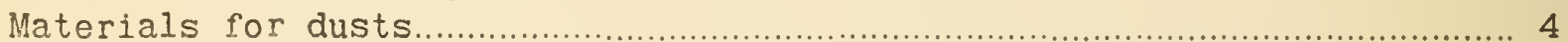

Materials for sprays....................................................................... 4

Relative effectiveness of dusts to specific cabbage insects.................. 5

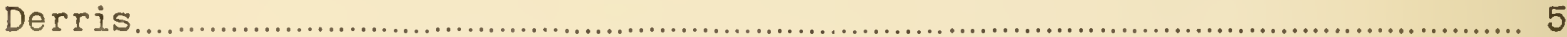

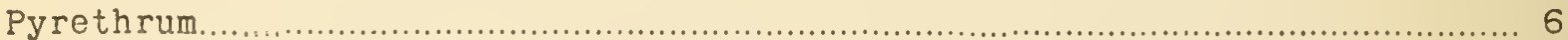

Pyrethrum-derris extracts in combination.............................................6. 6

Paris green dusts................................................................................. 7

Cryolite (sodium fluoaluminate) dusts................................................. 7

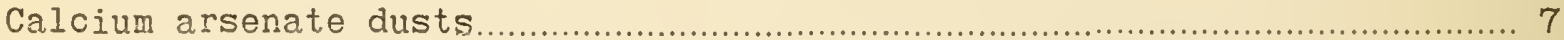

Cabbage worms on cauliflower, broccoli, kale, and collards....................... 7

Cutworms and corn earworms on cabbage.................................................... 8

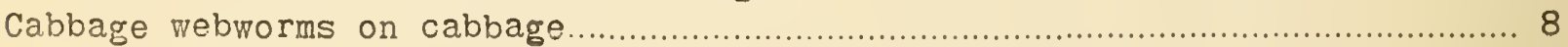

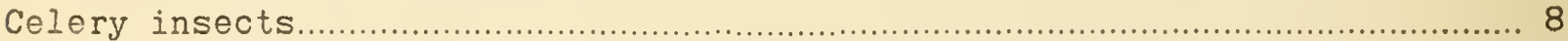

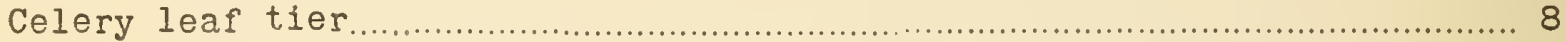

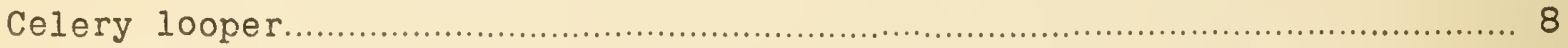

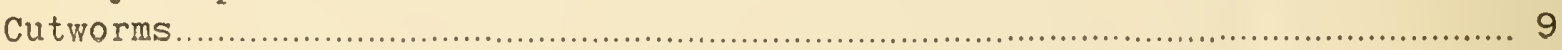

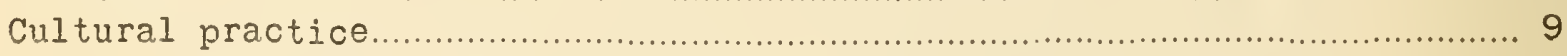

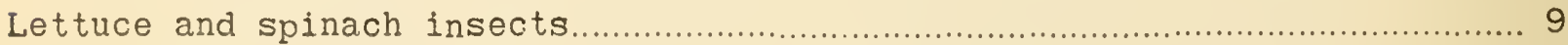

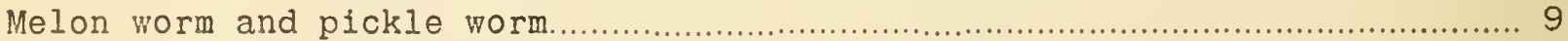

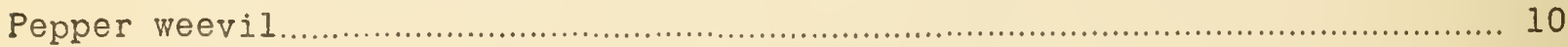

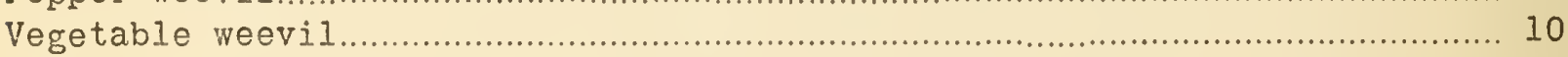

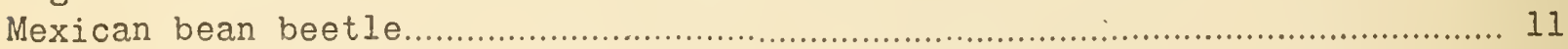

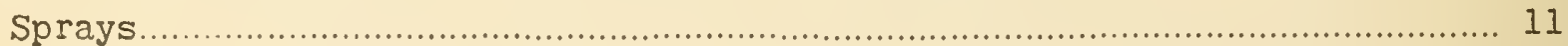

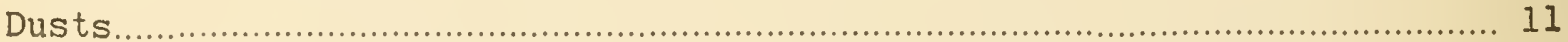

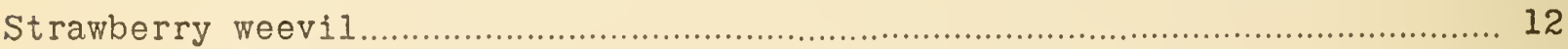

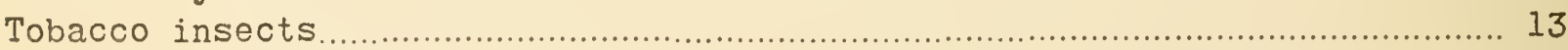

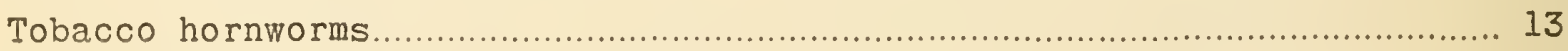

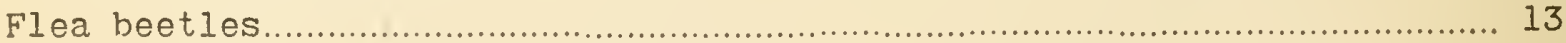

clean-up measures as an aid to control................................................. 14

Where to obtain insecticides................................................................ 14 


\section{INTRODUCTION}

This is a revision of multigraphed circular E-376, as issued by the Burtau in spril 1936. The developments of the 1936 season at the various laboratories of this Bureau have made desirable certain changes in the recommendations issued last year.

\section{LOCATION OF WORK}

This Bureau's researches on methods of control of certain insects, having for their oject the elimination of harmful insecticidal residues from the vegetable products, are being conducted at the following rield laboratories: Alnamra, Calip.. Baton Rouge, La., Biloxi, Miss.. Chadbourn, N. C., Charleston, S. C. Colurbus, Ohio, Sanford, Fla., and Phoenix, Ariz. The work on tobacco insects is being conducted at the following locations: Clarksville. Tenn., Quincy, Fla., Oxford, N. C., Florence, S. C., and Windsor, Conn.

\section{MATERIALS TESTED}

The recomendations incluaed in this circular are based principally upon tests with the following insecticides: Dusts: Commercially prepared or homemixed derris or cube root povider, pyrethrum powder. and cryolite (natural and synthetic), used with various diluents, paris green diluted with hydrated lime. and commercial calcium arsenate in the undiluted form and diluted with sulphur. Sprays: Derris or cube root powier in water, commercially prepared extracts of derris ard of pyrethrum and combinations of these materials, and cryolite (natural and synthetic).

\section{PRINCIPAL INSECTS INVOLVED}

The primcipal pests involved in these experiments are several kinds of lepidopterous larvae attacking cabbage and including the imported cabbage worm. the cabbage looper, the diamond-back moth, the cabbage webworm, the corn earrorm, and cutworms. Also the celery leaf tier, the Mexican bean beetle, the pepper weevil, the vegetable weevil, the melon worm, the pickle worm. the strawberry weevil, tobacco hornworms, and flea beetles.

\section{RECOMMENDATIONS FOR CONTROL}

The following recommendations are applicable only to certain crops on which harmful insecticidal residues may occur on the marketed product and are the best methods available that can be utilized and at the same time insure against harmful residues remaining on the product consumed by man.

It will be noted that lead arsenate is not recommended for the control of insects attacking any vegetable crop considered in this circular.

The use of other arsenicals and cryolite is, however, suggested as a control for certain insects on several of the crops uncier consideration. This sugzestion is made with the provision that the poison should not be used after the apoearance on the plant of fruit or foliage which will be sent to market or consumed, except in cases where it is definitely known that washing or stripping will remove all spray residues. 
In the interests of the industries concerned, it is strongly urged that the growers be warned of the poisonous nature of arsenicals and similar materials and that they take special precautions to be certain that such materials do not remain on the marketed product.

From the evidence at hand, the compounds of derris, cube, and pyrethrum, when applied at the dosages recommended herein, should not leave harmful residues on the market product. The active principles of these materials are rendered inert within a comparatively short time through the action of sunlight and exposure to the air, especially when spread thinly over the plants.

\title{
CABBAGE WORMS ON CABBAGE
}

As a general recommendation for the control of the imported cabbage worm, the cabbage looper, and the diamond-back moth on cabbage, the following materials (as dusts) are recommended in the order listed, at the dosages detailed later in this circular.

\section{Materials for dusts}

\author{
(1) Derris, \\ (2) Pyrethrum, \\ (3) Paris green, cryolite, calcium arsenate.
}

The dusts containing these materials should be applied in such a manner as to cover all infested portions of the plant, care being taken to reach the insects whenever possible. The rate of application may vary according to the Eize of the plants. Applications of 15 to 20 pounds per acre, per application, of the dust mixtures discussed later have given satisfactory results. Applications should be made in accordance with the more specific recommendations that follow; they should begin when the worms first appear and be repeated as often as necessary to protect the crop.

It is essential that the insecticides be applied when the worms are small, as the larger ones, especially the cabbage looper, are usually more difficult to kill. Furthermore, it is essential that the worms be killed before they have caused appreciable injury to the plants.

NOTE: Paris green, cryolite, and calcium arsenate should not be used on any portion of the cabbage plant that is to be marketed. This means that cabbage intended for marketing as U. S. Grade No. 1 (which allows four loose outer leaves) should not be poisoned with these materials aiter the head begins to form. If the marketed product is to bear a greater number of loose outer leaves than those allowed in the above grade, these materials should not be used after the plants have been thinned or transplanted.

\section{Materials for sprays}

In general, dusts have given better results than sprays in cabbage worm control. If desirable to use a spray, the following materials are recommended. Experiments to date have not indicated any special preference for 
either of these spray materials on the basis of their effectiveness.

(1) Derris root powder in water.

(2) Pyretirum extract, or pyrethrum-derris extract combined.

\section{Relative effectiveness of dusts to specific cabbage insects}

Based upon the relative efficiency, at the dosages recommended herein, of each of the insecticides tested, against each of the principal species of cabbage worms present, experiments indicate: (1) That as a control for the imported cabbage worm, derris is more effective than pyrethrum, paris green, cryoite, or calcium arsenate; (2) that derris and cryolite are approximately equal in effectiveness in controlling the cabbage looper, and that both materials are more effective than paris green, pyrethrum, or calcium arsenate; (3) that derris and calcium arsenate are approximately equal in effectiveness in controling the larvae of the diamond-back moth, while pyrethrum, cryolite. and paris green are relatively less effective for this species.

\section{Derris}

Derris dusts.--Derris dusts containing 0.5 to 1.0 percent of rotenone have given very promising results in four sections of the Central, Eastern, and Southern States. Satisfactory diluents for the derris root powder are such nonalkaline materials as finely ground tobacco dust, finely ground inert clay, talc, diatomaceous earth, infusorial earth, wheat flour, dusting gypsun, kaolin (china clay), and finely ground dusting sulphur. Some of these diluents have the advantage of being more economical in cost and more readily available in sorne sections of the country than in others. Indications are that derris retains its insecticidal value for a period of only approssmately 1 week in the field, under ravorable weather conditions, although further work must be done before definite conclusions can be reached upon this point. Satisfactory results were also obtained with commercial dusts containing approximately 0.5 percent of rotenone.

The rotenone content of derris root varies, and purchases should be made on the basis of rotenone content, total extractives, and degree of fineness. For example, a derris root powder containing 4 percent rotenone should contain not iess than 14 percent total carbon-tetrachloride or cther extractives. In general, the total extract (either by carbon tetrachloride or ether) should average approximately three and one-half times the rotenone content. The derris root powcer should be of such degree of rineness that not less than 90 percent of it will pass through a sieve having 200 meshes per linear inch, and all of the material ( 100 percent) should pass through a sieve having 80 meshes per linear inch.

The rotenone content of the finished mixed dust depends, of course, on tive quantity of diluent used as well as on the percentage of rotenone in the original material. Insecticide companies now sell high-grade, finely ground derris powder of specified rotenone content made by blending the various analyzed batches. 
formula:

To prepare a dust containing 1 percent of rotenone, use the following
Derris powder ( 4 percent rotenone)
$25 \mathrm{Ibs}$
(1 part by weight)
Diluent
75 Ibs. (3 parts by weight)

To prepare a dust containing 0.5 percent of rotenone, use the followjng formula:
Derris powder (4 percent rotenone) Diluent
$12 \frac{1}{2}$ lbs. (I part by weight)
87表 lbs. (7 parts by weight)

If the rotenone content of the derris powder is greater or less than 4 percent, the proportions of inert diluent must be varied accordingly. For example, a derris powder containing 5 percent of rotenone should be mixed with 4 parts of the diluent by weight, that is, 20 pounds of the derris powder containing 5 percent of rotenone and 80 pounds of the diluent, to obtain a 1-percent rotenone dust.

Derris dusts have also giver an indication that they may aid in the control of certain aphids, as well as flea beetles which infest cabbage and related crops.

Derris sprays.--Good control has been obtained with derris root powder (containing 4 percent of rotenone) in water at the rate of 2 to $2 \frac{1}{2}$ pounds per 50 gallons ô water, giving a rotenone content in the spray ranging from 0.02 to 0.025 percent. If the rotenone content of the derris powder is greater or less than 4 percent, the amount of the powder used should be varied accordingly in order to give the above indicated strengtins of 0.02 to 0.025 percent rotenone content in the spray. For example, if the derris root powder contains 5.5 percent rotenone, $1 \frac{1}{2}$ pounds of the powder should be used to give the desired content in the spray. Under some conditions it may be necessary to add a nonalkaline spreader or sticker to the spray, such as high-grade liquid or powdered neutral coconut oil soap, miscible pine oil, or one of the sulphonated oils.

\section{Pyrothrum}

Pyrethrum dusts.--Pure fresh pyrethrum dust, containing approximately 0.9 percent total pyrethrins, diluted with 2 to 3 parts of the same diluents, by weight, as recommended for use with derris dust, have shown promising results. For the most effective results it is essential that applications of this materiai should be made late in the afternoon or early in the evening.

Pyrethrun sprays. - Fairly satisfactory results have been obtained by the use of commercial pyrothrum extracts. These extracts vary as to their pyrethrin content. The directions given by the manufacturer should be used as a basis for the dilution of these materials.

Pyrethrum-derris extracts in combination

Fairly satisfactory results have been obtained with commercially prepared extracts of pyrethrum and derris in combination. The directions given by the manufacturer should be used as a basis for the dilution of these materials. 
Paris green dusts

Resulte indicate that paris green is more effective as a dust than as a spray when us $d$ at a dilution of 1 pound to 9 pounds of hydrated lime, applied at a rate of 20 pounds per acre, per application, until the plant begins to head, provid I the headed cabbage is stripped to four loose outer or wrapper leaves when being prepared for market. If the marketed product is to bear a greater number of loose outer leaves than those allowed in the above grade, paris green should not be used after the plants have been thinned or transplanted.

\section{Cryolite (sodium fluoaluminate) dusts}

Both sinthetic and natural cryolite prepared for insecticidal purposes have given favorable results when mixed with from 1 to 2 parts of the diluents mentioned for derris dusts. The same cara should be exercised to avoid harmful residues from cryolite, as has been prescribed for arsenicals.

\section{Calcium arsenate dusts}

Results with commercial calcium arsenate, for cabbage worm control, have shown a varia ion in the toxicity of various brands of this arsenical. Calcium arsenate, in the undiluted form, gave fairly satisfactory results when appliad at the rate of 15 to 20 pounds per acre per application. On account of the harmful residue hazard, this material. is subject to the same limitations mentioned for paris green and cryolite.

\section{CABBAGE WORMS ON CAULIFLOWER, BROCCOLI, KALE, AND COLLARDS}

The Bureau has not yet had an opportunity to conduct any extensive experiments on the control of cabbage worms on cauliflower, broccoli, kale, or collards. In general, it is believod thet the derris and pyrethrum compounds should give the same results on these crops as when used on cabbage, provided a good coverage of the affected parts of the plant can be obtained.

Preliz nary experiments in California have shown that derris, or cube, or pyrethrum dust mixtures, at the same dilutions as have been mentioned for cabbage, gav, as satisfactory results in the control of the three more common species of cabbage worms on cauliflower as they did on cabbage. It was found to be especis lly important, however, to start the treatments early in the development of the cauliflower, while the plants were small, since it was not possible to nbtain a gond coverage of the insecticides over the heavy foliage of nearly mature cauliflower plants. Good results were also obtained against cabbage worms on cauliflower with sprays of derris root powder containing from 0.02 to 0.025 percent of rotenone ( $v i z, 2$ to $2 \frac{1}{2}$ pounds of derris root powder containing 4 percent of rotenone per 50 gallons of water).

The experiments of 1934 on collards indicate that each of the three more common species of cabbage worms may be controlled satisfactorily with a derris dust mixture containing 0.5 percent of rotenone. Less satisfactory results were obtained witl pyrethrum powder containing 0.9 percent total pyrethrins, diluted 
with 5 parts of the same materials as mentioned for derris aust. It should be emphasized that arsenicals are not recommended for cabbage worm control on these crops, owing to the poisonous residues likely to remain on the edible portion, and because less satisfactory results were obtained with arsenicals.

\section{CUTWORMS AND CORN EARWORMS ON CABBAGE}

In certain sections of the country, especially during the fall season, several species of cutworms and the corn earworm are sometimes more abundant and cause mor. damage to the foliage of cabbage than do the usually more prevalent species of "green" cabbage worms. Neither derris nor pyrethrum, at the dilutions tested, has been effective in combating cutworms or the corn earworm on cabbage. When such cutworm infestations are expected, a standard cutworm poisoned bait should be used before the crop is set in the field, or, in cases where seed is planted, the treatments should be made before the plants appear above the ground. The early treatments can be followed by later treatments, care being exercised to prevent the bait from lodging on any portion of the plants that are to be marketed. When the corn earworm is present in destructive abundance on cabbage, dust applications of paris green, calcium arsenate, or cryolite should be made, at the strengths recommended in this circular, before the plants begin to head.

\section{CABBAGE WEBWORMS ON CABBAGE}

Results of experiments during 1936 indicate that the cabbage webworm can be controlled by applications of dust containing 0.5 percent of rotenone, provided applications are made auring the early stages in the growth of the insects and of the plants. In these treatments, the cabbage plants should be covered thoroughly with the dust.

\section{CELERY INSECTS}

\section{Celery leaf tier}

The celery leaf tier is the major pest of celery in the Florida producing area, and also periodically becomes troublesome in the North and in California. This pest can be controlled by careful treatments with pyrethrum dust, the dust being mixed with an equal quantity by volume of tobacco dust. The treatment consists of making two applications within a period of one-half hour. The object of making the second treatment within such a period is to kill those worms which have moved from the web as a result of the first treatment. Approximately 25 pounds of the mixture per acre are necessary for each application. Except under unusual conditions in the Florida area, one treatment, that is, two applications at a ialf-hour interval, is sufficient to protect any one given area of celery.

Arsenicals are not satisfactory as a control for this pest.

\section{Celery looper}

Several species of loopers attack celery. In Florida these pests are usually held in check by a bacterial disease, and observations so far would indicate that ordinarily no artificial control measures are necessary. These 
pests succumb readily to treatments of pyrethrum powder as recommended for the celery leaf tier, and arsenical applications are not necessary.

\section{Cutworms}

The use of a poisoned bait is the only practicable means for the control of the majority of the species of cutworms attacking celery. The risk from poison residue can be eliminated by distributing one of the standard cutworm baits between the rows, provided care is taken to keep the bait from falling on the plants.

In the Florida celery district the southern armyworm is usually considered as a cutworm, inasmuch as it exhibits similar habits in the late stages of its development. The successful control of this species, however, depends on the prompt application of an arsenical at the time the eggs are hatching. Paris green added to the regular bordeaux mirture and applied when the presence of the young worms is first detected may be used, provided no applications are made on plants which will be harvested within a period of less than 6 weeks. From 1 to 2 pounds of paris green per 100 gallons of bordeaux mixture have been used successfully.

\section{Cultural practice}

Under Florida conditions, the cleaning up of the crop refuse during harvest is valuable in pest control, particularly of the celery leaf tier.

\section{LETTUCE AND SPINACH INSECTS}

There are several leaf-feeding forms which may attack lettuce and spinach, and on occasion cause considerable damage. Pyrethrum or derris is recommended as a substitute for the arsenicals in the control of these pests, using the same dosages as given for cabbage worms.

\section{MELON WORM AND PICKLE WORM}

The incications are that the melon worm and the pickle worm may be controlled satisactorily on squash in the coastal areas of North Carolina and South Carolina, and probably elsewhere when the returns from the crop will justify the axpense involved, by dusting with a derris-sulphur mixture containing from 1 to 1.5 percent of rotenone. In instances of light to moderate infestation the 1-percent or even 0.5 -percent strength rotenone dust should be sufficient if it is applied early and regularly. Where the infestation is heavy the 1.5-percent dust should be used. While finely ground dusting sulphur seems to be the most effective diluent for derris powder for use in melon worm and pickle worm control on squash, this material may cause slight injury to the foliage of this crop. The addition of from 10 to 25 percent of tobacco dust, clay, or talc to the derris-sulphur misture will improve its dusting qualities.

The treatments should be begun when the worms first appear on the leaf buas of the squash plant, which may be within a week or 10 days after the plants appear above ground, and continued at 7-day intervals as long as the worms aro present or tho crop is being harvested. The rate of application will depend 
upon the size of the plants and should range from 15 to 25 pounds per acre. Extreme care should be exercised to see that the growing tips of the plants are well covered with the dust, as the worms feed extensively on the young leaf buds before tunneling into the fruit, stem, and vines.

Pyrethim powder has also proved of some value in the control of these pests. The pyrethrum powder should be used in a mixture with clay or talc and dusting sulprur, equal parts of the pyrethrum and the diluent being used.

Cryolite, mixed with clay and finely ground dusting sulphur in the ratio of 1 pound of cryolite to 1 pound of clay and 2 pounds of sulphur, may be used to advantage in early treatments. In order to avoid danger of poisonous residues on the warket product, treatment with this material should not be made after the fruit has begun to set.

Calcium arsenate has not proved satisfactory as a poison for the melon worm or pickle worm.

A bellows-type duster is more satisfactory for the treatment of the squash crop than a duster of the rotary type because of the method of planting and the necessity of applying the material directly to the growing tips of the plant. In the case of crops producing extensive vines, a duster of the rotary type may be more satisfactory.

\section{PEPPER WEEVIL}

While the pepper weevil can be controlled by treating the crop at regular intervals with undiluted calcium arsenate, or with equal parts of calcium arsenate and hydrated lime, this method is not to be recommended unless the residue can be adequately removed by washing. Excessive applications of calcium arsenate may result in heavy infestations of plant lice which are capable of causing more crop loss than pepper weevil infestations. Such aphid infestations may be controlled with nicotine dust applied alone, or mixed with the calcium arsenate.

For conditions which obtain in California, cultural control is recommended. This involves complete destruction of pepper plants after harvest, and also the clea - up of nightshade plants and eggplants in the vicinity of pepper fields, the nightshade being a favorite winter host of the pepper weevil. The pepper fields should be plowed at least by January 1, and all nightshade plants destroyed by the loth of January. This gives a period between the destruction of the winter host plants and the planting of the seed bed in excess of the time that pepper weevils are able to live on other than their normal host plants. No experiments have been conducted on the control of the pepper weevil in New Mexico or Texas, and no recommendations are made for the control of this pest in these two areas.

\section{VEGETABLE WEEVIL}

The vegetable weevil is a pest of vegetable crops in certain sections of Alabama, Arkansas, California, Florida, Georgia, Louisiana, Mississippi, and Texas. It is also known to occur in Tennessee and South Carolina. The following methods are recommended for its control: 
(1) Poisoned baits scattered lightly between rows and on headlands as soon as the rirst damage by the adults is noticed. The bait that has been most effective consists of 1 pound of sodium fluoride. 15 pounds of wheat bran, 8 pounds of freshly choppec turnips or carrots, and sufficient water to form a mash. Appiy late in the afternoon to prevent excessive drying out of the bait. The bait should be made up several hours in advance of application.

(2) Crop rotation where possible, to avoid building up infestations through continuous cropping with favorite host plants.

(3) The treatment of seed beds, such as tomato and cabbage, or young field-set plants, and crop remnants after harvest. with arsenicals or fluorine compounds is advocated. Arsenicals or fluorine compounds should not be applied to turnips, mustard, or similar crops, the leaves of which are intended for food.

(4) Field sanitation. All rubbish and weeds where the insect may find shelter during inactive periods should be cleaned up.

\section{MEXICAN BEAN BEETLE}

Finely ground derris or cube root, as well as cryolite, are recommended for the control of the Mexican bean bette.

\section{Sprays}

Ground derris or cube having a rotenone content of 4 percent should be used at a dosage of $1 \frac{1}{2}$ pounds in 50 gallons of water or at a rate of $1 \frac{1}{2}$ ounces in 3 gallons. This gives a rotenone content of approximately 0.015 percent. Derris or cube of different rotenone content may be used in the proper proportion so as to make the finished spray of a content of 0.015 percent rotenone. If the ground root contains a higher percentage of rotenone than 4 percent, decrease the dosage proportionately. For instance, if a 5 percent rotenonecontent derris or cube powder is on hand, use only four-fifths as much, namely. approximately $1 \frac{1}{4}$ pounds to 50 gallons or $1 \frac{1}{4}$ ounces to 3 gallons.

Extensive tests indicate that no spreader or sticker is necessary with derris or cube in water for use on beans.

Cryolite, either natural or synthetic, may be used at a dosage of 3 pounds in 50 gallons of water, or 3 ounces in 3 gallons. When cryolite is used. treatments with this material should stop when pods begin to form.

\section{Dusts}

Growers who prefer to dust or are not equipped to spray will obtain rairly satisfactory results with any of the following dust mixtures:

Derris powder or cube powder way be mixed with one of the following diluents or carriers and used in dust form: Talc. finely ground dusting sulphur, inert clay, tobacco dust, kaolin (china clay), or other inert, finely 
ground material. The finished dust should contain 0.5 percent of rotenone, that is, $12 \frac{1}{2}$ pounds of 4-percent derris or cube and $87 \frac{1}{2}$ pounds of carrier or diluent. Finely ground sulphur is of value against the common red spider, the potato leafhopper on bean, powdery mildew, and the Mexican bean beetle and is to be preferred when any of these are present in injurious numbers. It is likely to flow too freely from many dusting machines, and care should be taken not to apply unnecessarily heavy dosages with consequent higher costs. Twenty to 25 pounds to the acre per application is the recommended dosage. The use of hoods or trailers, constructed from barboo poles and barrel hoops and covered with muslin, 10 feet long, lised one to the row behind power or traction dusters, makes possible a considerable saving in the dosage.

Commercial rotenone-bearing dusts usually contain 0.5 percent to 0.75 percent of rotenone and are prepared to be used as dusts. These mixtures should not be used for spraying, unless the label on the package indicates that a diluent has been used which will mix readily with water.

Except in semi-arid regions, plant injury often results from the use of calcium arsenate mixtures on beans. Lead arsenate should never be used on bean foliage because serious injury and reductions in yields often result from its use, even when combined with bordeaux mixture.

The beans should be sprayed or dusted when adults are found in the field or when egg masses become numerous on the underside of the leaves. One to three, sometimes four, applications are required, depending on the abundance of the insect. The beans must be treated on the underside of the leaves, and care should be taken that the spraying or dusting is done thoroughly.

Cultural control. - The destruction of crop remnants after harvest is as important as thorough spraying or dusting. Plow under all plant remnants at least 6 inches deep.

\section{STRAWBERRY WEEVIL}

The hibernation habits of the strawberry weevil in North Carolina are such that the destruction of the weevil by burning over its hibernating areas is a most effective means of reducing losses from attacks of this pest. This burning is necessary only over areas within 100 feet of the strawberry field, as observations have shown that 97 percent of the weevils hibernate within 100 feet of the cultivated areas. The burning should be carried on in the winter and not in the spring, and every precaution should be taken to prevent such fire from getting out of control.

When the burning method can not be applied, satisfactory control of the strawberry weevil may be obtained by dusting with a mixture consisting of 1 pound of calcium arsenate and 5 pounds of finely ground dusting sulphur. The first application should be made as soon as the weevil appears in the field. The rate of application will range from 10 to 30 pounds per acre per application, depending upon the density of the strawberry planting. Ordinarily two applications are sufficient to protect the early fruit. All applications of poison dusts should be discontinued at least 3 weeks prior to the ripening of 
th $\theta$ first berries, because, where a long bearing season obtains, the treatment with an arsenical poison after this period may result in harmful residues on the ripened berries. In preliminary tests, both derris and pyrethrum powder, applied as dusts, have shown promising results in controlling this insect.

\section{TOBACCO INSECTS}

Although tobacco is not a food, it would appear that arsenical or other poisonous residues on tcbiccs leaves may be harmful or undesirable to the consumer, and therefore cvary preciuticn should be taken to keep residues resulting from the use of insecticides on tobacco at a minimum. For this reason, lead arsenate is no longer recommended for use on tobacco.

\section{Tobacco hornworms}

A fairly satisfactory remedy for tobacco hornworms consists of a mixture of paris green 1 part and slaked lime 6 parts. This dust should be applied with a hand-operated crank duster for small acreages and a small traction duster for farms growing as much as 20 acres of tobacco, at the rate of 7 to 8 pounds per acre, per application, the rate depending upon the size and type of tobacco. Especial care should be observed in the manipulation of the crank duster in order to obtain a satisfactory coverage, while at the same time keeping the rate of application as low as possible. The dust gun nozzle should be held in the center of the space between the tobacco rows and not aimed directly at the foliage. This precaution is essential to avoid placing heavy deposits of paris green on certain leaves, which would cause serious burning.

Tobacco grown under shade cloth in Florida and Connecticut is protected to a large degree from hornworm attack by the cloth walls and tops of the shade structure. Efforts should be made to keep the cloth intact throughout the growing season. The 1 to 6 mixture of paris green and lime may be used if applied with care. The rate of application should be about 4 pounds of the mixture per acre for each treatment.

Fall and winter plowing, by which process the overwintering pupae are destroyed, is an effective cultural control for reducing the population of hornworms in tobacco. Hand picking of the worms, where the acreage is limited. can be practiced to advantage, especially with low-priced labor.

\section{Flea beetles}

The most satisfactory control for flea beetles attacking tobacco is a derris or cube dust containing 1 percent of rotenone. These dusts are obtained by diluting derris or cube powder to the desired strength with a clay dilue:.2. The following dosages of dust are recommended for each application:

For plant beds, $\frac{1}{2}$ pound per 100 square yards, applications to be repeated every 4 days until control is obtained. For nowly set plants, 3 to 5 pounds per acre, applications to be repeated every 4 days until control is obtained. For the growing tobacco crop, 6 to 10 pounds per acre, depending upon the size of the plants, applications to be repeated every 7 days until control is obtained. 
In shade-grown tobacco when joint infestations of flea beetles and grasshoppers appear on newly set plants, barium fluosilicate is recommended. This material should be applied at the rate of 3 to 5 pounds per acre for each application. The clay diluents used for dusts to be applied on tobacco sometimes leave a whitish deposit on cigar-wrapper leaves grown under shade. This is undesirable, and sterilized tobacco dust has been found to be a satisfactory substitute for the clay diluents for use on the shade tobaccos. If tobacco dust is used, the manufacturer should certify that the dust has been sterilized and that it is free of pathogenic organisms which might spread tobacco diseases.

\section{CLEAN-UP MEASURES AS AN AID TO CONTROL}

Emphasis should be placed un the thorough cleaning up of crop remnants after harvest. It has been observed, in the southern producing areas particularly, that fields of harvested cabbage and similar crops serve as a source of infestation to new plantings.

\section{WHERE TO OBTAIN INSECTICIDES}

Information regarding the purchase of the insecticide materials mentioned in this circular may be obtained usually through local dealers in agricultural supplies, seedsmen, general stores, drug and department stores, or through the county agricultural agent, State agricultural experiment station, State department of agriculture, or Bureau of Entomology and Plant Quarantine, U. S. Department of Agriculture. 